\title{
Cells as vehicles for therapeutic genes to treat liver diseases
}

\author{
J Prieto $^{1,2}$, V Fernandez-Ruiz ${ }^{1}$, MP Kawa ${ }^{1}$, P Sarobe $^{1}$ and C Qian ${ }^{1}$ \\ ${ }^{1}$ Center for Applied Medical Research (CIMA), University of Navarra, Pamplona, Spain and ${ }^{2}$ CIBERehd, Clinica Universitaria de \\ Navarra, University of Navarra, Spain
}

\begin{abstract}
Gene therapy involves the transfer of genetic sequences to tissues to obtain a curative effect. Effective gene transfer can be achieved by introducing the therapeutic gene into viruslike particles that facilitate the penetration of the transgene into the cells. However, direct injection of viral vectors may activate innate immunity leading to toxic effects. On the other hand, viral vectors frequently induce neutralizing antibodies, which limit the efficacy of repeated vector administration. Moreover, targeting of the transgene to the desired tissue is a goal that not always can be attained with current vectors. The use of cells as vehicles for therapeutic genes may offer solutions for these issues. Ex vivo transduction of specific cells with vectors encoding therapeutic genes followed by injection of the engineered cells to the patient will reduce the inherent toxicity of the vector while preventing the development of neutralizing antibodies. At the same time, this
\end{abstract}

Keywords: cancer; liver diseases; progenitor cells; EPC

\section{Introduction}

Gene therapy has emerged as an efficient procedure to treat human diseases. This method is based on the transfer of genetic material to tissues to induce a curative effect. Gene therapy vectors are molecular constructs used to facilitate the penetration of the therapeutic genetic material inside the cells. Vectors are frequently generated from viral genomes, which are modified to eliminate their pathogenic properties and adapted to transport the therapeutic gene(s). Non-viral vectors have, in general, lower transduction efficiency than virusbased vectors. Viral vectors have, however, several limitations when administered directly to the patient. They may cause significant toxicity by activating innate immunity or by eliciting an adaptive immune response against viral proteins. In the former case, a systemic inflammatory reaction (which may be lethal) can occur and in the latter case, the transduced cells can be eliminated by activated $\mathrm{T}$ cells leading to tissue damage and abrogation of transgene expression. ${ }^{1}$ On the other side, when the vector is injected directly into the subject,

Correspondence: Professor J Prieto, Center for Applied Medical Research (CIMA), Clinica Universitaria de Navarra, 36 Avda. Pio XII, Pamplona 31008, Spain.

E-mail: jprieto@unav.es

Received 13 February 2008; revised 18 February 2008; accepted 19 February 2008; published online 3 April 2008 therapeutic approach can take advantage of the homing properties of the transduced cells to target transgene expression to the sites of interest. Thus, it has been shown that administration of dendritic cells engineered ex vivo with vectors encoding selected antigenic determinants or immunostimulatory molecules is an efficient means to elicit protective immune responses. Similarly, since endothelial progenitor cells (EPC) move to inflammed, ischemic or neoplastic tissues, the injection of EPC transduced ex vivo with appropriate therapeutic genes is an effective method to direct transgene expression to the lesions to be treated. Promising data in animal models of disease point to a future clinical application of this therapeutic strategy.

Gene Therapy (2008) 15, 765-771; doi:10.1038/gt.2008.44; published online 3 April 2008

it can stimulate the production of neutralizing antibodies making re-treatment ineffective. ${ }^{1}$ In addition, targeting the vector to the desired site is an issue when given systemically.

In recent years, the use of specific cell types transduced ex vivo with gene therapy vectors and then injected into the patient has generated a great deal of interest. This combination of cell and gene therapy has several appealing aspects. One of the advantages is that specific cell types serving as vehicles for therapeutic genes can be attracted to the desired locations by chemotactic factors produced at the site of tissue injury or inflammation. Neutrophils, for instance, express the chemokine receptors CXCR1 and CXCR2 and are directed to tissues with acute or chronic inflammation by chemokines CXCL8/interleukin (IL)-8 (which interacts with both CXCR1 and CXCR2) and CXCL1 (selective for CXCR2) produced in the inflammatory milieu. It is conceivable that ex vivo arming of neutrophils with cytoprotective or antifibrogenic genes followed by systemic administration of these engineered cells may be a useful approach to reduce inflammatory organ damage or excessive fibrogenesis in inflammed organs (Pereboeva L, personal communication).

The use of cells as vehicles for therapeutic genes has other additional advantages. The administration of genemodified cells instead of viral particles to the patient prevents the direct interaction of the vector with Toll-like 
receptors, thus avoiding activation of innate immunity. This would reduce or abolish the inflammatory reaction, which frequently follows treatment with recombinant viruses contributing to better tolerance of the therapy. Similarly, it is expected that neutralizing antibodies will be a less problem when using transduced cells as therapy.

Combining cell and gene therapy demands the development of methodologies for efficient gene transfer to the purified cell population, which is to be employed as gene carrier. In a pioneer work, Pereboev et al. ${ }^{2}$ were able to increase considerably the transduction efficiency of dendritic cells (DCs) with adenoviral vectors using an 'adapter' to enhance the interaction of the virus with the cell membrane. This adapter protein consists of the ectodomain of CAR (the cell receptor for adenovirus) fused to mouse CD40 ligand through a trimerization motif-fibritin. This adapter was able to bind both human and mouse CD40 and adenoviral fiber knob. Incubation of adenoviral vector with the adapter not only dramatically increased the transduction efficiency of DCs, but also induced their maturation as reflected by a marked increase in the synthesis of IL-12 upon incubation of the cells with adapter-coated adenovirus. ${ }^{2}$ As in the case of DCs and adenoviruses, adapters can also be designed for other cell types (neutrophils, endothelial progenitor cells (EPCs), and so on) and for other viral vectors.

In this short review, we will focus mainly in the use of two cell types as vehicles for therapeutic genes to treat liver diseases: DCs and EPCs.

\section{Induction of antitumor and antiviral immunity using engineered DCs}

DCs have been widely employed as cell vehicles for genes subservient immunotherapeutic purposes in patients and animal models of liver diseases. These cells are professional antigen-presenting cells having important functions: sensing the presence of pathogens and linking innate and acquired immunity by presenting antigens to $\mathrm{T}$ cells. ${ }^{3}$ DCs monitor their environment becoming activated upon antigen encounter or during inflammation caused by pathogens. This process, also known as maturation, leads to upregulation of $\mathrm{MHC}$, adhesion and co-stimulatory molecules, as well as to expression of cytokines, chemokines and chemokine receptors, which increase the ability of DCs to migrate to lymph nodes and to attract and activate T-cells. Due to these properties, DCs have been considered for the formulation of cell vaccines potentially useful for the treatment of liver tumors and chronic hepatitis caused by hepatitis B (HBV) and C viruses (HCV). For these applications, DCs can be genetically modified to enhance their immunostimulatory potential.

Concerning genetic modification of DCs for antitumor therapy, two main approaches have been used: expression of genes of tumor antigens which can serve as potential targets for $\mathrm{T}$ cells, or expression of genes of cytokines and molecules enhancing T-cell functions. In the former case, DCs are transfected with previously well-characterized tumor antigens before administration to animals or patients. Antigens expressed by tumor cells or by antigen-presenting cells in the tumor environment are poorly immunogenic. Consequently, administration of ex vivo-activated DCs can potentially overcome the lack of immunogenicity of tumor antigens. The most widely used antigen for inmmunotherapy of hepatocellular carcinoma is alpha-fetoprotein, ${ }^{4-6}$ which is produced by many liver tumors. Tumor antigens commonly expressed by gastrointestinal malignancies, such as carcinoembryonic antigen and mucin 1,7 have also been used to treat metastatic liver cancer. Different type of vectors have been employed to transduce DCs, including lentivirus, ${ }^{8}$ vaccinia virus ${ }^{7}$ and adenovirus. ${ }^{4,5,9}$ Adenoviruses have frequently been employed, as they not only infect DCs but also induce DCs maturation. ${ }^{10}$ In some cases, DCs have been transfected using mRNA from the tumor extract,, $11-13$ a procedure useful when the relevant tumor antigen is unknown. Besides tumor antigens, genes encoding cytokines and/or costimulatory and adhesion molecules have also been transferred to DCs. IL-12 and IL-18 ${ }^{14,15}$ are the main cytokines in the first group, due to their ability to shift T-cell responses towards a Th1 profile, whereas CD80, ICAM-1 or LFA-1 belongs to the second group. ${ }^{16}$ In some cases, to enhance both antigen expression and DCs function, the cells have been simultaneously transduced with genes encoding tumor antigens, cytokines and/or costimulatory molecules, resulting in higher DC activation and more intense $\mathrm{T}$-cell responses than when using single-gene transduction. ${ }^{7,17}$

In a recent clinical trial conducted in patients with advanced primary or metastatic liver cancer, monocyte-derived DCs engineered with adenoviral vector encoding IL-12 were injected directly into the tumor. ${ }^{18}$ In this trial, 3 monthly doses of the transduced cells were administered, and it was expected that, after intratumoral injection, DCs would take up tumor antigens and migrate to regional lymph nodes to stimulate an antitumor T-cell response that would be facilitated by the in situ production of IL-12. In this trial, the observed antitumor effect was very poor. By radioactive labeling of the cells and single photon emission computed tomography imaging, it was demonstrated that DCs did not migrate to lymph nodes, but were retained inside the tumor mass. The authors showed that tumor nodules produced high levels of IL-8, which possibly forced DCs expressing CXCR1 and CXCR2, to remain at the place of the injection, failing to orchestrate antitumor immunity. These results indicate that engineered DCs should be rather pulsed with tumor extracts ex vivo and then injected inside or in the vicinity of lymph nodes.

In chronic viral infections caused by $\mathrm{HBV}$ and $\mathrm{HCV}$, different reports have proposed the use of DCs transduced with genes encoding viral antigens as a possible therapeutic vaccination. As in the case of tumors, the expression of genes of viral antigens by DCs transduced and activated ex vivo, can result in fully functional antigen presentation, which may overcome the tolerance to viral proteins found in patients with chronic infection. Due to the ability of some viral genes to interfere with the cell machinery responsible for DC function, an important issue in this approach is the choice of the appropriate antigen to elicit effective immune responses. In fact, it has been demonstrated that under certain circumstances, expression of viral genes, such as core and E1 from HCV, may impair DC functions, and as a consequence, induction of T-cell responses. ${ }^{19,20}$ Thus, besides a good 
immunogenicity, viral antigens to be produced in DC should lack these immunosuppressive properties. In the case of HBV, surface antigen is usually the preferred antigen, ${ }^{21-23}$ although core and $X^{24,25}$ have also been used. Similarly, for HCV, non-structural 3 (NS3) protein, ${ }^{26-30}$ and to a lesser extent core protein, ${ }^{26,27,31}$ have been employed. In all cases, the selected antigens should be those that in the course of natural infection provoke immune responses capable of clearing the pathogen. Again, adenoviruses have been the vectors of choice for gene transfer to $\mathrm{DCs},{ }^{26-31}$ although other systems have been utilized including adeno-associated viruses, ${ }^{25}$ retroviruses $^{24}$ and mRNA transfection. ${ }^{31}$ By employing this strategy, DCs transfected with viral genes have demonstrated a remarkable ability to induce antiviral T-cell responses both in vitro and in vivo, being in some cases stronger than those obtained by direct administration of the vector encoding the viral antigen. ${ }^{30}$ There is, therefore, a need for pilot clinical trials to determine whether the injection of transduced DCs could be an effective procedure for therapeutic vaccination against $\mathrm{HCV}$ and HBV virus infections. This vaccination modality would allow repeated doses of the vaccine without the limitation imposed by the development of neutralizing antibodies.

\section{Bone marrow-derived endothelial progenitor cells as carriers of therapeutic genes}

In 1997, Asahara and cols ${ }^{32}$ described the existence of EPC in peripheral blood from normal adult individuals. This cell population represents less than 1/10000 circulating mononuclear cells and less than $1 \%$ of the cells from the bone marrow (BM). EPC derived from hemangioblast, which is a common precursor of both hematopoietic cells and endothelial cells. Abundant evidence has been provided to show that EPCs contribute to neovascularization of adult tissues in pathological conditions such as tumors and ischemic

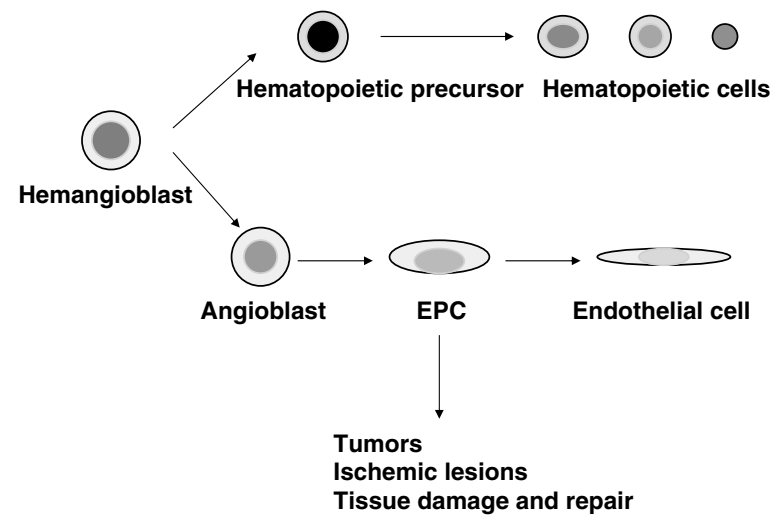

Figure 1 Differentiation and function of endothelial progenitor cell (EPC). BM-derived EPCs are of hematopoietic origin and possibly derive from the hemangioblast, which is also hematopoietic precursor to generate hematopoietic cells. The growth factors such as vascular endothelium growth factor differentiate hemangioblast to angioblast, EPC and finally to endothelia cells. These cells are involved in the tumor angiogenesis, ischemic lesions and tissue damage and repair. lesions of the heart or extremities and also in situations of tissue damage and repair (Figure 1). ${ }^{33}$ It is now accepted that the neovascularization process in the adult can take place not only by activation and sprouting of pre-existing endothelium, a process known as angiogenesis, but also by recruitment to the new vessels of circulating EPC, a process named vasculogenesis. This latter process occurs not only in the embryonic period of life but also in pathological conditions in the adult.

EPCs are recruited to the sites of ischemia or tissue injury by the local production of chemotactic molecules such as vascular endothelium growth factor (VEGF) and stem-cell-derived factor- 1 . The synthesis of these factors is stimulated by the expression in ischemic tissues and damaged organs of hypoxia-inducible factor-1. EPCs express receptors for VEGF, especially VGFER2 (or KDR), and for stem-cell-derived factor-1, namely CXCR4. The ligand-receptor interaction promotes EPC migration to injured organs where they actively participate in tissue repair. ${ }^{33-37}$ At the site of tissue damage, EPCs secrete a variety of cytoprotective and angiogenic factors including insulin-like growth factor 1, VEGF, hepatocyte growth factor and stem-cell-derived factor-1. ${ }^{38}$ As mentioned below, EPC have been considered as a potentially useful therapy to treat acute and chronic liver conditions. For this purpose, the production of insulin-like growth factor 1 and hepatocyte growth factor is of great interest as these factors exert both hepatoprotective and antifibrogenic effects. ${ }^{39}$

EPCs are characterized by the expression of cell surface markers characteristic of hematopoietic cells (CD133), stem cells (CD34) and endothelial cells (VEGFR2). By culturing BM-derived mononuclear cells in medium containing specific factors, two types of EPCs are generated: early and late EPCs. The former appear after 7 days of culture and produce growth factors abundantly, while the latter appear after 4-6 weeks of culture, have high clonogenic capability and produce scarcity of growth factors. ${ }^{40}$ The former have been most frequently used to stimulate tissue repair. Different molecules, some of them generated at the site of injury, facilitate the mobilization of EPC from BM to peripheral circulation. ${ }^{41,42}$ Stem-cell-derived factor-1, VEGF, granulocyte-macrophage colony-stimulating factor, granulocyte colony-stimulating factor and erythropoietin have significant EPC-mobilizing activity.

For therapeutic purposes, EPC can be obtained from $\mathrm{BM}$ or from peripheral blood, ${ }^{2-4}$ either by selection of CD133+ cells using immunomagnetic procedures or by culturing mononuclear cells in specific culture medium. ${ }^{33-35}$ The therapeutic potential of EPC in stimulating liver regeneration has recently been demonstrated in a clinical trial performed at the University of Dusseldorf. The authors showed that administration of $2-10 \times 10^{7}$ CD133+ cells obtained from BM aspirate after selection with immunomagnetic procedure and given by intraportal administration (through catheter placed in the veins of segment II and III) was able to significantly accelerate the regeneration of the left liver lobe following right portal embolization in patients that were to undergo right hepatectomy. ${ }^{43}$

In animals, many studies have shown that EPC (both of human and rodent origin) can be used with success to treat ischemic lesions of the heart and limbs. ${ }^{44,45}$ Suh and co-workers reported that human EPC obtained by 
culturing in specific medium peripheral blood mononuclear cells and given to nude mice induced an acceleration of wound healing by local production of growth factors, stimulation of tissue repair and neovascularization. ${ }^{46}$ In 2006, Taniguchi et al. ${ }^{47}$ showed that EPC obtained from human peripheral blood mononuclear cells or from murine BM after culture in specific medium for 10 days and given intrasplenically were able to ameliorate acute carbon tetrachloride liver damage in nude mice (human EPC) or in BALB/c mice (murine EPC) and to improve survival. They demonstrated that EPC generated high levels of hepatocyte growth factor, VEGF and heparin-binding EGF-like growth factor and stimulated the endogenous production of VEGF. ${ }^{47}$ The same group reported in 2007 that EPC (characterized by the expression of CD133, VEGFR2, Tie-2 and CD31) given intravenously were able to reduce significantly liver damage and fibrogenesis in a model of liver cirrhosis induced by chronic administration of carbon tetrachloride. $^{48}$ In our group, ${ }^{49}$ we observed that intrasplenic injection of EPC resulted in marked improvement and long-term survival of mice injected with an adenovirus encoding CD40L, a model of fulminant hepatitis with $100 \%$ mortality. ${ }^{50}$

Neovascularization plays a critical role in the growth and metastatic spread of tumors and involves recruitment of circulating EPC from BM as well as sprouting of preexisting endothelial cells. EPCs have been detected at increased frequency in the circulation of cancer patients and lymphoma-bearing mice, and tumor volume and tumor production of VEGF were found to correlate with EPC mobilization. ${ }^{51,52}$ A recent study has shown that mobilized EPCs participate in tumor vasculogenesis of hepatocellular carcinoma. AC133 gene or antigen (marker of EPC) in peripheral blood and liver tissue could be used as a biomarker for predicting the progression of hepatocellular carcinoma. ${ }^{53}$ Moreover, when EPCs are administered to immunocompromized mice, they incorporate into the vasculature of xenotransplanted tumors. ${ }^{54,55}$ Our recent data showed that EPCs can be transduced by lentiviral and adenoviral vectors. Immunohistochemical and immunofluorescence analysis showed that EPCs were incorporated in the tumor tissues in animal model with orthotopic tumor models (Figure 2). The in vivo imaging for luciferase expression demonstrated that EPCs were recruited preferentially by tumor nodules and that the maximal recruitment occurred at days 2-5 day after EPC administration (Figure 2). ${ }^{56}$ These data show that EPC are attracted to tumors and could serve as vehicles for genes encoding antitumor factors to be expressed inside the tumor mass.

From what has been exposed, EPCs are recruited both to sites of tissue injury and to neoplastic lesions. This property makes EPCs useful tools to convey therapeutic genes to diseased organs in patients with tissue damage or neoplastic conditions. ${ }^{57}$ However, the number of EPC that can be obtained for clinical use is scarce and may be insufficient for specific applications. Moreover, in some circumstances such as diabetes or obesity EPCs may be dysfunctional. It is therefore of great interest to develop means to enhance the therapeutic potential of a limited number of EPC or to revert EPC dysfunction. Recently, it has been proposed that genetic engineering of EPC aimed at increasing the production of growth factors, promoting their cytoprotective properties or extending their life span

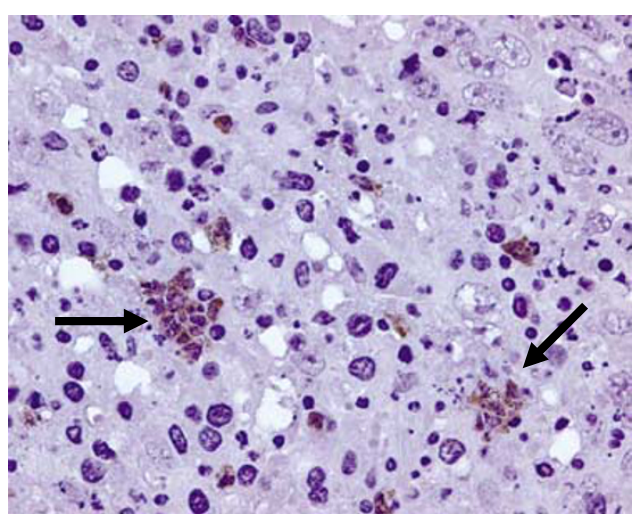

Figure 2 Recruitment of endothelial progenitor cell (EPC) transduced by adenoviral vector encoding firefly luciferase reporter gene in orthotopic liver cancer. C57BL/6 mice received MC38 colon carcinoma cells to induce a liver tumor. After 10 days, $10^{6}$ of EPC transduced with adenovirus expressing luciferase were intravenously injected into tumor-bearing animals. Luciferase-positive EPC are recruited by the tumor being detected by immunohistochemistry using antibody against luciferase. Arrows indicate luciferase positive cells.

is an effective procedure to improve the curative effects of EPC. ${ }^{58}$ Choi et al. ${ }^{59}$ showed that inhibition of glycogen synthase kinase-3 $\beta$ (GSK3 $\beta$ ) signaling pathway led to increased nuclear translocation of $\beta$-catenin and increased secretion of angiogenic cytokines (VEGF and IL-8). It enhanced the survival and proliferation of early EPC, whereas it promoted the survival and differentiation of late EPC. Transplantation of either of these genetically modified EPC into the ischemic hindlimb model of athymic nude mouse significantly improved blood flow, limb salvage and tissue capillary density compared with nontransduced EPC. ${ }^{59}$ In an animal model of experimentally induced limb ischemia, Iwaguro el al. ${ }^{60}$ showed that administration of EPC transduced with adenovirus encoding VEGF improved neovascularization and blood flow recovery and reduced amputation rate. In this study, EPC-mediated adenoviral VEGF gene therapy was able to achieve curative effects despite the use of subtherapeutical EPC doses. ${ }^{60}$ Thus, combined EPC and gene therapy is an option to address the problem of limitations in the number of EPC that can be obtained for clinical applications.

Genetic engineering of EPCs may also be beneficial in aged individuals where EPC function is impaired due to senescence. In these cases, cell therapy may be inefficient despite adequate EPC mobilization from BM. It should be noted that EPC are not true pluripotent self-renewing stem cells, but a committed lineage and therefore are subjected, as other somatic cells, to limited number of cell divisions. Only true stem cells express telomerase reverse transcriptase (TERT) and are able to replicate indefinitely as they maintain telomeric DNA replication. These cells can divide beyond Hayflick limit without experiencing senescence. ${ }^{61}$ Gene transfer of TERT to differentiated cells such as fibroblast has been shown to confer unlimited replicative potential without inducing malignant transformation. ${ }^{62}$ It has been shown that TERT gene transfer to endothelial cell lines was able to confer resistance to programmed cell death and senescence, and to result in increased functional competence. ${ }^{58}$ Murasawa et al. ${ }^{63}$ have demonstrated that telomerase 
activity contributes to EPC angiogenic properties: mitogenic activity, migratory activity and cell survival. This enhanced regenerative activity of EPCs by hTERT transfer will provide a novel therapeutic strategy for postnatal neovascularization in patients with severe ischemic disease and to improve the biological performance of EPC in aged individuals.

\section{Prospective}

Although combination of cell and gene therapy shows great promise for therapy of different types of diseases, several issues should be considered for future clinical applications. The first is the choice of vectors for cell transduction. The selected vector should enable high transduction efficiency and should be devoid of any damaging effect on cell viability. If the cells divide actively an integrative vector should be considered. In some cases, according to the type of the transgene, vectors with inducible promoters will be necessary. Second, for a diversity of applications, the cell fate after transplantation should be monitored using adequate in vivo imaging systems such as positron emission tomography or single photon emission computed tomography. Third, future development of combined cell and gene therapy implies a full understanding of the impact of the cell vehicle and transgene in the pathogenesis of the specific disease we wish to treat.

\section{References}

1 Thomas CE, Ehrhardt A, Kay MA. Progress and problems with the use of viral vectors for gene therapy. Nat Rev Genet 2003; 4: 346-358.

2 Pereboev AV, Nagle JM, Shakhmatov MA, Triozzi PL, Matthews $\mathrm{QL}, \mathrm{Kawakami} \mathrm{Y}$ et al. Enhanced gene transfer to mouse dendritic cells using adenoviral vectors coated with a novel adapter molecule. Mol Ther 2004; 9: 712-720.

3 Banchereau J, Steinman RM. Dendritic cells and the control of immunity. Nature 1998; 392: 245-252.

4 Vollmer Jr CM, Eilber FC, Butterfield LH, Ribas A, Dissette VB, Koh A et al. Alpha-fetoprotein-specific genetic immunotherapy for hepatocellular carcinoma. Cancer Res 1999; 59: 3064-3067.

5 Gonzalez-Carmona MA, Marten A, Hoffmann P, Schneider C, Sievers E, Schmidt-Wolf IG et al. Patient-derived dendritic cells transduced with an a-fetoprotein-encoding adenovirus and cocultured with autologous cytokine-induced lymphocytes induce a specific and strong immune response against hepatocellular carcinoma cells. Liver Int 2006; 26: 369-379.

6 Zhang HM, Zhang LW, Ren J, Fan L, Si XM, Liu WC. Induction of alpha-fetoprotein-specific CD4- and CD8-mediated T-cell response using RNA-transfected dendritic cells. Cell Immunol 2006; 239: 144-150.

7 Madan RA, Arlen PM, Gulley JL. PANVAC-VF: poxviral-based vaccine therapy targeting CEA and MUC1 in carcinoma. Expert Opin Biol Ther 2007; 7: 543-554.

8 Wang B, He J, Liu C, Chang LJ. An effective cancer vaccine modality: lentiviral modification of dendritic cells expressing multiple cancer-specific antigens. Vaccine 2006; 24: 3477-3489.

9 Chan RC, Pang XW, Wang YD, Chen WF, Xie Y. Transduction of dendritic cells with recombinant adenovirus encoding HCA661 activates autologous cytotoxic T lymphocytes to target hepatoma cells. Br J Cancer 2004; 90: 1636-1643.

10 Morelli AE, Larregina AT, Ganster RW, Zahorchak AF, Plowey JM, Takayama $\mathrm{T}$ et al. Recombinant adenovirus induces maturation of dendritic cells via an NF-kappaB-dependent pathway. J Virol 2000; 74: 9617-9628.

11 Zhang L, Zhang H, Liu W, Wang H, Jia J, Si X et al. Specific antihepatocellular carcinoma $\mathrm{T}$ cells generated by dendritic cells pulsed with hepatocellular carcinoma cell line HepG2 total RNA. Cell Immunol 2005; 238: 61-66.

12 Peng BG, He Q, Liang LI, Xie BH, Hua YP, Chen ZB et al. Induction of cytotoxic T-lymphocyte responses using dendritic cells transfected with hepatocellular carcinoma mRNA. $\mathrm{Br} J$ Biomed Sci 2006; 63: 123-128.

13 Zhang HM, Zhang LW, Liu WC, Cheng J, Si XM, Ren J. Comparative analysis of DC fused with tumor cells or transfected with tumor total RNA as potential cancer vaccines against hepatocellular carcinoma. Cytotherapy 2006; 8: 580-588.

14 Satoh Y, Esche C, Gambotto A, Shurin GV, Yurkovetsky ZR, Robbins PD et al. Local administration of IL-12-transfected dendritic cells induces antitumor immune responses to colon adenocarcinoma in the liver in mice. J Exp Ther Oncol 2002; 2: 337-349.

15 Iinuma H, Okinaga K, Fukushima R, Inaba T, Iwasaki K, Okinaga A et al. Superior protective and therapeutic effects of IL-12 and IL-18 gene-transduced dendritic neuroblastoma fusion cells on liver metastasis of murine neuroblastoma. J Immunol 2006; 176: 3461-3469.

16 Hodge JW, Rad AN, Grosenbach DW, Sabzevari H, Yafal AG, Gritz L et al. Enhanced activation of T cells by dendritic cells engineered to hyperexpress a triad of costimulatory molecules. J Natl Cancer Inst 2000; 92: 1228-1239.

17 Cao DY, Yang JY, Dou KF, Ma LY, Teng ZH. Alpha-fetoprotein and interleukin-18 gene-modified dendritic cells effectively stimulate specific type-1 CD4- and CD8-mediated T-Cell response from hepatocellular carcinoma patients in vitro. Hum Immunol 2007; 68: 334-341.

18 Mazzolini G, Alfaro C, Sangro B, Feijoo E, Ruiz J, Benito A et al. Intratumoral injection of dendritic cells engineered to secrete interleukin-12 by recombinant adenovirus in patients with metastatic gastrointestinal carcinomas. J Clin Oncol 2005; 23: 999-1010.

19 Sarobe P, Lasarte JJ, Casares N, Lopez-Diaz de Cerio A, Baixeras $\mathrm{E}$, Labarga $\mathrm{P}$ et al. Abnormal priming of $\mathrm{CD} 4(+) \mathrm{T}$ cells by dendritic cells expressing hepatitis $\mathrm{C}$ virus core and $\mathrm{E} 1$ proteins. J Virol 2002; 76: 5062-5070.

20 Sarobe P, Lasarte JJ, Zabaleta A, Arribillaga L, Arina A, Melero I et al. Hepatitis $C$ virus structural proteins impair dendritic cell maturation and inhibit in vivo induction of cellular immune responses. J Virol 2003; 77: 10862-10871.

21 Qiu SJ, Lu L, Qiao C, Wang L, Wang Z, Xiao X et al. Induction of tumor immunity and cytotoxic $t$ lymphocyte responses using dendritic cells transduced by adenoviral vectors encoding HBsAg: comparison to protein immunization. J Cancer Res Clin Oncol 2005; 131: 429-438.

22 Huang Y, Chen Z, Jia H, Wu W, Zhong S, Zhou C. Induction of $\mathrm{Tc} 1$ response and enhanced cytotoxic $\mathrm{T}$ lymphocyte activity in mice by dendritic cells transduced with adenovirus expressing HBsAg. Clin Immunol 2006; 119: 280-290.

23 Yang JY, Cao DY, Liu WC, Zhang HM, Teng ZH, Ren J. Dendritic cell generated from CD34+ hematopoietic progenitors can be transfected with adenovirus containing gene of HBsAg and induce antigen-specific cytotoxic $\mathrm{T}$ cell responses. Cell Immunol 2006; 240: 14-21.

24 Ding CL, Yao K, Zhang TT, Zhou F, Xu L, Xu JY. Generation of cytotoxic $\mathrm{T}$ cell against $\mathrm{HBcAg}$ using retrovirally transduced dendritic cells. World J Gastroenterol 2003; 9: 1512-1515.

25 You H, Liu Y, Cong M, Ping W, You C, Zhang D et al. HBV genes induce cytotoxic T-lymphocyte response upon adeno-associated virus (AAV) vector delivery into dendritic cells. J Viral Hepat 2006; 13: 605-612. 
26 Li W, Krishnadas DK, Li J, Tyrrell DL, Agrawal B. Induction of primary human $\mathrm{T}$ cell responses against hepatitis $\mathrm{C}$ virusderived antigens NS3 or core by autologous dendritic cells expressing hepatitis $C$ virus antigens: potential for vaccine and immunotherapy. J Immunol 2006; 176: 6065-6075.

27 Li W, Li J, Tyrrell DL, Agrawal B. Expression of hepatitis C virusderived core or NS3 antigens in human dendritic cells leads to induction of pro-inflammatory cytokines and normal T-cell stimulation capabilities. J Gen Virol 2006; 87 (Part 1): 61-72.

28 Xiang M, Eisenbach C, Lupu CM, Ernst E, Stremmel W, Encke J. Induction of antigen-specific immune responses in vivo after vaccination with dendritic cells transduced with adenoviral vectors encoding hepatitis C virus NS3. Viral Immunol 2006; 19: 210-219.

29 Yu H, Babiuk LA, van Drunen Littel-van den Hurk S. Immunity and protection by adoptive transfer of dendritic cells transfected with hepatitis C NS3/4A mRNA. Vaccine 2007; 25: 1701-1711.

30 Zabaleta A, Llopiz D, Arribillaga L, Silva L, Riezu-Boj JI, Lasarte $\mathrm{JJ}$ et al. Vaccination against hepatitis $\mathrm{C}$ virus with dendritic cells transduced with an adenovirus encoding NS3 protein. Mol Ther 2008; 16: 210-217.

31 Matsui M, Moriya O, Abdel-Aziz N, Matsuura Y, Miyamura T, Akatsuka $\mathrm{T}$. Induction of hepatitis $\mathrm{C}$ virus-specific cytotoxic $\mathrm{T}$ lymphocytes in mice by immunization with dendritic cells transduced with replication-defective recombinant adenovirus. Vaccine 2002; 21: 211-220.

32 Asahara T, Murohara T, Sullivan A, Silver M, van der Zee R, Li T et al. Isolation of putative progenitor endothelial cells for angiogenesis. Science 1997; 275: 964-967.

33 Iwami Y, Masuda H, Asahara T. Endothelial progenitor cells: past, state of the art, and future. J Cell Mol Med 2004; 8: 488-497.

34 Smadja DM, Cornet A, Emmerich J, Aiach M, Gaussem P. Endothelial progenitor cells: characterization, in vitro expansion, and prospects for autologous cell therapy. Cell Biol Toxicol 2007; 23: 223-239.

35 Young PP, Vaughan DE, Hatzopoulos AK. Biologic properties of endothelial progenitor cells and their potential for cell therapy. Prog Cardiovasc Dis 2007; 49: 421-429.

36 Khakoo AY, Finkel T. Endothelial progenitor cells. Annu Rev Med 2005; 56: 79-101.

37 Murasawa S, Asahara T. Endothelial progenitor cells for vasculogenesis. Physiology (Bethesda) 2005; 20: 36-42.

38 Urbich C, Aicher A, Heeschen C, Dernbach E, Hofmann WK, Zeiher AM et al. Soluble factors released by endothelial progenitor cells promote migration of endothelial cells and cardiac resident progenitor cells. J Mol Cell Cardiol 2005; 39: 733-742.

39 Sanz S, Pucilowska JB, Liu S, Rodríguez-Ortigosa CM, Lund PK, Brenner DA et al. Expression of insulin-like growth factor I by activated hepatic stellate cells reduces fibrogenesis and enhances regeneration after liver injury. Gut 2005; 54: 134-141.

40 Ribatti D. The discovery of endothelial progenitor cells. An historical review. Leuk Res 2007; 31: 439-444.

$41 \mathrm{Li} \mathrm{B}$, Sharpe EE, Maupin AB, Teleron AA, Pyle AL, Carmeliet P et al. VEGF and PIGF promote adult vasculogenesis by enhancing EPC recruitment and vessel formation at the site of tumor neovascularization. FASEB J 2006; 20: 1495-1497.

42 Korbling M, Reuben JM, Gao H, Lee BN, Harris DM, Cogdell D et al. Recombinant human granulocyte-colony-stimulating factor-mobilized and apheresis-collected endothelial progenitor cells: a novel blood cell component for therapeutic vasculogenesis. Transfusion 2006; 46: 1795-1802.

43 Furst G, Schulte am Esch J, Poll LW, Hosch SB, Fritz LB, Klein M et al. Portal vein embolization and autologous CD133+ bone marrow stem cells for liver regeneration: initial experience. Radiology 2007; 243: 171-179.

44 Kalka C, Masuda H, Takahashi T, Kalka-Moll WM, Silver M, Kearney $\mathrm{M}$ et al. Transplantation of ex vivo expanded endothelial progenitor cells for therapeutic neovascularization. Proc Natl Acad Sci USA 2000; 97: 3422-3427.

45 Kocher AA, Schuster MD, Szabolcs MJ, Takuma S, Burkhoff D, Wang $\mathrm{J}$ et al. Neovascularization of ischemic myocardium by human bone-marrow-derived angioblasts prevents cardiomyocyte apoptosis, reduces remodeling and improves cardiac function. Nat Med 2001; 7: 430-436.

46 Suh W, Kim KL, Kim JM, Shin IS, Lee YS, Lee JY et al. Transplantation of endothelial progenitor cells accelerates dermal wound healing with increased recruitment of monocytes/macrophages and neovascularization. Stem Cells 2005; 23: 1571-1578.

47 Taniguchi E, Kin M, Torimura T, Nakamura T, Kumemura H, Hanada $S$ et al. Endothelial progenitor cell transplantation improves the survival following liver injury in mice. Gastroenterology 2006; 130: 521-531.

48 Nakamura $T$, Torimura $T$, Sakamoto $M$, Hashimoto $O$, Taniguchi E, Inoue $\mathrm{K}$ et al. Significance and therapeutic potential of endothelial progenitor cell transplantation in a cirrhotic liver rat model. Gastroenterology 2007; 133: 91-107.

49 Fernández-Ruiz V, Kawa M, Iñiguez M, Berasain C, Qian C, Prieto J. Prevention and treatment of acute liver injury in animal models by endothelial progenitor cells. Hepatology 2007; 46: 248A.

50 Schmitz V, Dombrowski F, Prieto J, Qian C, Diehl L, Knolle P et al. Induction of murine liver damage by overexpression of CD40 ligand provides an experimental model to study fulminant hepatic failure. Hepatology 2006; 44: 430-439.

51 Mancuso P, Burlini A, Pruneri G, Goldhirsch A, Martinelli G, Bertolini F. Resting and activated endothelial cells are increased in the peripheral blood of cancer patients. Blood 2001; 97: 3658-3661.

52 Monestiroli S, Mancuso P, Burlini A, Pruneri G, Dell'Agnola C, Gobbi A et al. Kinetics and viability of circulating endothelial cells as surrogate angiogenesis marker in an animal model of human lymphoma. Cancer Res 2001; 61: 4341-4344.

53 Yu D, Sun X, Qiu Y, Zhou J, Wu Y, Zhuang L et al. Identification and clinical significance of mobilized endothelial progenitor cells in tumor vasculogenesis of hepatocellular carcinoma. Clin Cancer Res 2007; 13: 3814-3824.

54 Lyden D, Hattori K, Dias S, Costa C, Blaikie P, Butros L et al. Impaired recruitment of bone-marrow-derived endothelial and haematopoietic precursor cells blocks tumor angiogenesis and growth. Nature Med 2001; 7: 1194-1201.

55 Asahara T, Masuda H, Takahashi T, Kalka C, Pastore C, Silver $\mathrm{M}$ et al. Bone marrow origin of endothelial progenitor cells responsible for postnatal vasculogenesis in physiological and pathological neovascularization. Circ Res 1999; 85: 221-228.

56 Fernández V, Kawa M, Yang G, Prieto J, Qian C. Bone marrow derived endothelial progenitor cells engineered by lentiviral vectors as therapeutic antitumoral strategy. Mol Ther 2006; 13: S373.

57 Oh HK, Ha JM, O E, Lee BH, Lee SK, Shim BS et al. Tumor angiogenesis promoted by ex vivo differentiated endothelial progenitor cells is effectively inhibited by an angiogenesis inhibitor, TK1-2. Cancer Res 2007; 67: 4851-4859.

58 Murasawa S, Asahara T. Gene modified cell transplantation for vascular regeneration. Curr Gene Ther 2007; 7: 1-6.

59 Choi JH, Hur J, Yoon CH, Kim JH, Lee CS, Youn SW et al. Augmentation of therapeutic angiogenesis using genetically modified human endothelial progenitor cells with altered glycogen synthase kinase-3beta activity. J Biol Chem 2004; 279: 49430-49438.

60 Iwaguro H, Yamaguchi J, Kalka C, Murasawa S, Masuda H, Hayashi $\mathrm{S}$ et al. Endothelial progenitor cell vascular endothelial growth factor gene transfer for vascular regeneration. Circulation 2002; 105: 732-738. 
61 Simonsen JL, Rosada C, Serakinci N, Justesen J, Stenderup K, Rattan SI et al. Telomerase expression extends the proliferative life-span and maintains the osteogenic potential of human bone marrow stromal cells. Nat Biotechnol 2002; 20: 592-596.

62 Milyavsky M, Shats I, Erez N, Tang X, Senderovich S, Meerson A et al. Prolonged culture of telomerase-immortalized human fibroblasts leads to a premalignant phenotype. Cancer Res 2003; 63: 7147-7157.

63 Murasawa S, Llevadot J, Silver M, Isner JM, Losordo DW, Asahara T. Constitutive human telomerase reverse transcriptase expression enhances regenerative properties of endothelial progenitor cells. Circulation 2002; 106: 1133-1139. 